\title{
Colonoscopy Quality Assessment
}

\author{
Nabil F. Fayad ${ }^{1,2}$, Charles J. Kahi ${ }^{1,2}$ \\ 1. Division of Gastroenterology and Hepatology, Department of Medicine, Indiana University School of \\ Medicine, Indianapolis, Indiana. \\ 2. Section of Gastroenterology and Hepatology, Medicine Department, Richard L. Roudebush VA \\ Medical Center, Indianapolis, Indiana.
}

\section{Corresponding Author:}

Nabil F. Fayad, M.D.

Associate Professor of Clinical Medicine

Division of Gastroenterology and Hepatology, Department of Medicine

Indiana University School of Medicine

\&

Richard L. Roudebush VA Medical Center

1481 W. 10th St., Room 111G

Indianapolis, Indiana 46202

Email: nfayad@iu.edu

Telephone: $317-988-3120$

Fax: 317-988-5313

This is the author's manuscript of the article published in final edited form as:

Fayad, N. F., \& Kahi, C. J. (2015). Colonoscopy Quality Assessment. Gastrointestinal Endoscopy Clinics of North America, 25(2), 373-386. https://doi.org/10.1016/j.giec.2014.11.008 


\section{Keywords:}

Colorectal cancer- Colonoscopy- Quality- Measures- Adenoma detection rate.

\section{Abstract:}

Colonoscopy is the cornerstone of colorectal cancer screening programs. There is significant variability in the quality of colonoscopy between endoscopists. Colonoscopy quality assessment tracks various metrics in order to improve the effectiveness of colonoscopy, aiming at reducing the incidence and mortality from colorectal cancer. Adenoma detection rate is the prime metric, as it is associated with the risk of interval cancers. Implementing processes to measure and improve the adenoma detection rate is essential to improve the quality of colonoscopy. 


\section{Introduction:}

Colonoscopy is the cornerstone of colorectal cancer (CRC) screening programs, whether used as the primary modality or as a follow up to another screening test ${ }^{1}$. Therefore, adequate prevention of CRC relies heavily on colonoscopy.

While studies from the 1990 's indicate that colonoscopy could prevent up to $90 \%$ of $\mathrm{CRC}^{2-4}$, more recent studies suggest that the reduction in CRC incidence might be lower, particularly in the right colon ${ }^{5-9}$. Interval CRCs (or post-colonoscopy CRCs) account for $3.4 \%$ to $9 \%$ of all cases of CRCs and are primarily encountered in the right colon ${ }^{10-15}$.

Whereas several factors could contribute to limited effectiveness of colonoscopy ${ }^{16}$, data suggest that endoscopist-related factors are the most important element ${ }^{17-19}$. In fact, $71 \%$ to $86 \%$ of interval cancers can be attributed to colonoscopist-related factors, as they represent missed lesions or result from incompletely resected lesions ${ }^{20-23}$.

These concerns have led to an increased emphasis on improving the quality of colonoscopy to maximize its ability to reduce CRC incidence. . The Gastroenterology societies have proposed various indicators of colonoscopy quality ${ }^{24}$. Choosing and measuring the most appropriate metric(s) to assess the quality of colonoscopy for practitioners, and improving them when required, remain a work in progress. This chapter discusses the value and limitations of potential quality metrics and considerations for implementing them in practice to improve colonoscopy performance.

\section{Colonoscopy Quality Process Measures:}


The debate continues regarding the ideal quality measure for colonoscopy, as each of the indicators has its advantages and its drawbacks 25,26 . It is no longer debated though that colonoscopy performance should be regularly assessed for every endoscopist ${ }^{27,28}$. While adenoma detection rate (ADR) is largely viewed as the best validated practical outcome measure ${ }^{25-29}$, two other process measures warrant consideration.

\section{Cecal Intubation Rate:}

The use of cecal intubation rate as a quality metric derives from recognizing that colonoscopists should have the ability to perform a complete examination to the cecum in the large majority of procedures ${ }^{30}$. Based on established benchmarks, effective colonoscopists should be able to intubate the cecum in $\geq$ $90 \%$ of all cases, including $\geq 95 \%$ of screening colonoscopies in healthy adults ${ }^{24}$.

While data from the late 1990 s revealed that this benchmark was achieved in only $55 \%$ of practitioners in North America ${ }^{31}$, more recent evidence suggest improved cecal intubation rates; a study of 10 endoscopists from the University of Maryland found rates ranging between $88 \%$ and $97 \%$, except for one endoscopist with a cecal intubation rate of $63 \%^{32}$. This study highlights the importance of measuring cecal intubation rates (and similarly other metrics) to identify outliers.

Failure to routinely intubate the cecum is in fact one of the reasons that limit colonoscopy's effectiveness; a study from Japan and another from New Zealand found that interval cancers were due to failure to reach the cecum, in $27 \%$ and $54 \%$ of cases respectively ${ }^{33,34}$. Further, Baxter et al found that patients who undergo colonoscopy by endoscopists with cecal intubation rates $\geq 95 \%$ were less likely to have interval cancers compared to patients who undergo colonoscopy by endoscopists with intubation 
rates $<80 \%$ (distal OR, 0.73; $95 \% \mathrm{Cl}, 0.54-0.97$; proximal $\mathrm{OR}, 0.72 ; 95 \% \mathrm{Cl}, 0.53-0.97)^{12}$. Thus, evaluating cecal intubation rates is a first step towards assessing quality colonoscopy.

\section{Withdrawal Time:}

Spending sufficient time between intubating the cecum and removing the colonoscope from the patient is necessary to perform a thorough mucosal inspection, with a low miss rate for significant lesions ${ }^{35}$. The suggested benchmark for withdrawal time (WT) is an average of at least 6 minutes in exams where no biopsies or polypectomies are performed (derived from a large number of colonoscopies in patients without prior surgical resection $)^{24}$.

The utility of WT as a quality measure has been somewhat disputed, as the evidence is contradictory about its correlation with adenoma or polyp detection rates ${ }^{19,36-39}$. Recently, the results of a large observational study from England, which included over 31000 colonoscopies, support the value of WT as a quality metric ${ }^{40}$. Colonoscopists with WT less than 7 minutes had significantly lower ADRs compared to those with WT of 11 minutes or longer $(42.5 \%$ vs $47.1 \%, p<0.001)$, with $50 \%$ less right-sided adenomas detected per procedure. The authors also found that there was no incremental benefit in ADR beyond 10 minutes of WT (which does not include duration of polyp removal). . Data from a recent abstract by Shaukat et al. suggest that WT might be a more sensitive indicator of interval cancer than ADR ${ }^{41}$. The authors analyzed records of over 76000 colonoscopies performed by 51 gastroenterologists in Minnesota; they found that colonoscopists' average annual WT were inversely associated with interval cancers $(p<0.0001)$, whereas physicians' ADR were not $(p=0.40)$. Compared to WT $>6$ minutes, the adjusted incidence rate ratio for $\mathrm{WT}<6$ minutes was $2.3(95 \% \mathrm{Cl}, 1.5-3.4 ; \mathrm{p}<0.0001)$. 
It remains likely though that longer mean WT reflects better withdrawal technique (including cleaning of residual fluid, adequate colonic distention and proper examination of proximal side of folds) ${ }^{42}$. Therefore, colonoscopy experts and the American Society for Gastrointestinal Endoscopy/ American College of Gastroenterology task force recommend the use of WT mainly as a quality indicator for colonoscopists who have low ADR, rather than a stand-alone metric ${ }^{24,30}$.

\section{Adenoma Detection Rate: The Core Outcome Measure:}

While it would be most meaningful to measure CRC incidence and mortality, or alternatively the incidence of interval cancers, as actual outcomes of colonoscopy ${ }^{2}$, these are not practical for timely quality interventions. Thus, ADR, or the proportion of screening colonoscopies where at least one adenoma is detected, has been proposed as the best, most reliable, and practical surrogate quality metric $^{24-26}$. Current ADR benchmarks are $\geq 25 \%$ for men and $\geq 15 \%$ for women ${ }^{24}$.

\section{ADR Correlation with Risk of Interval Cancer:}

Two large colonoscopy studies from Poland and from the US validated the ADR as a quality metric by clearly linking it to the risk of interval $\mathrm{CRC}^{43}, 44$. The Polish study was conducted by Kaminski et al between 2000 and $2004^{43}$. The authors evaluated 45,026 subjects undergoing screening colonoscopy, performed by 186 endoscopists. The results, published in 2010, showed that patients whose endoscopists had an ADR less than $20 \%$ were at least 10 times more likely to be diagnosed with an interval CRC, compared with those whose endoscopists had $A D R \geq 20 \%(p=0.008)$. Interval cancer risk 
increased as ADR decreased, and other than age, all other examined factors did not correlate with the risk of interval cancer.

The US study was carried by Corley et $\mathrm{al}^{44}$; the authors reviewed 314,872 screening colonoscopies performed between 1998 and 2010, by 136 high-volume gastroenterologists on patients in the Kaiser Permanente health plan. The results, published in 2014, showed that ADR is an independent predictor of interval CRC, with a Hazard Ratio of 0.52 (95\% Cl, 0.39-0.69) for patients whose exams were performed by colonoscopists with $A D R>33.5 \%$, compared with those whose colonoscopists had $A D R<19 \%$. Interval cancer risk decreased linearly with increasing endoscopist ADR, overall and separately in the proximal colon and in the distal colon, and there was no ADR threshold above which there was no further protective benefit; the risk of interval cancer decreased by $3 \%$ for each $1 \%$ increase in ADR (Hazard Ration 0.97; $95 \% \mathrm{Cl}, 0.96-0.98)$. In addition, the results revealed an inverse association between CRC mortality and ADR: patients who colonoscopists were in the highest ADR quintile had a $62 \%(95 \% \mathrm{Cl}$, $35 \%-88 \%)$ reduction in fatal CRC, as compared with patients whose physicians were in the lowest quintile.

\section{ADR Measurement:}

Measuring the ADR of every colonoscopist is a priority for colonoscopy quality improvement ${ }^{24}$. It should be noted though that a reliable ADR assessment likely require a large sample size of colonoscopies performed by the practitioner. In a mathematical model developed by Do et al, at least 500 procedures were needed in the ADR calculation to provide narrow 95\% confidence intervals, that accurately reflect performance $^{45}$. 
Nevertheless, ADR is relatively easy to measure, even when it requires manual chart reviews ${ }^{46}$. Despite a somewhat time-consuming process to periodically review pathology data, this is largely facilitated by an objective approach, limited to a binary query, i.e. presence or absence of adenoma- without further characteristics or count. Serrated lesions should not be counted toward the ADR. Added strength of ADR as a quality metric is that it indirectly reflects other factors, including WT, colonoscopist technique and motivation, and bowel preparation quality ${ }^{47}$.

The importance of ADR measurement is underscored by the wide rates variability among practicing colonoscopists, ranging from less than $10 \%$ to over $50 \%{ }^{17,36,43,44,48}$. The impact of the endoscopist on ADR is substantial, accounting for up to 10 -fold difference between colonoscopists, and exceeding the effect of age or gender ${ }^{17}$. The baseline colonoscopy is decisive for effective CRC screening, as it impacts initial clearance from neoplastic lesions, and also dictates subsequent surveillance intervals ${ }^{30}$. Therefore, colonoscopists with high ADR provide their patients with double-protection: more complete baseline clearance, and shorter surveillance intervals. Thus, assessing and improving ADR is at the core of a successful CRC prevention program.

\section{Polyp Detection Rate:}

Polyp detection rate (PDR) has received some attention as a surrogate for ADR, as it is automatically collected by colonoscopists while generating procedure reports and/or billing codes, making it more practical to measure than ADR. PDR was validated as a surrogate to ADR by two studies by Williams et $\mathrm{al}^{49,50}$. In the first study conducted at a single academic institution, the authors showed a strong correlation between ADR and PDR (correlation 0.86, $p<0.001)^{49}$. In the second study, which included sixty endoscopists at multiple practice sites, they found again a high correlation between colonoscopists' 
PDR and ADR in both men and women (correlation 0.91, $p<0.001$ ), as well as a correlation between PDR and advanced adenoma detection ${ }^{50}$.

In addition, Baxter et al carried out a large observational study in Ontario, Canada, which showed an association between the PDR and the incidence of interval cancers in the right colon ${ }^{12}$. Patients who underwent colonoscopy by endoscopists with PDR $\geq 30 \%$ were less likely to have proximal interval cancers, compared to patients whose colonoscopists had PDR $<10 \%(\mathrm{OR}, 0.61 ; 95 \% \mathrm{Cl}, 0.42-0.89$, $p<0.0001)$

To date, there is no prospective study that evaluates PDR as a quality measure, and there are two main predicaments that can hinder the use of PDR. First, there are no recommended benchmarks from the leading US Gastroenterology societies; potentially, the targets suggested by Williams et al can be used ( $40 \%$ for men and $30 \%$ for women- based on correlation with ADR targets of $25 \%$ for men and $15 \%$ for

women, respectively $)^{49,50}$, but these still await official endorsement. Second, PDR is much more prone to corruptibility, by resection of non-neoplastic diminutive polyps or by biopsy of normal tissue; which, as suggested once again by Williams et al, require periodical audits ${ }^{49}, 50$ - and these could negate its practicality to some extent.

\section{Adenoma Detection Rate: Limitations:}

Expecting colonoscopy to prevent all cases of CRC is unrealistic; however, its effectiveness is based on the ability of endoscopists to detect the vast majority of neoplastic lesions and to remove them completely. While ADR has certainly proven to be a reliable metric of colonoscopy quality, it can be criticized for its inability to gauge if a colonoscopist is leaving behind additional adenomas, other precancerous lesions, or fragments of identified/ resected adenomas. 


\section{Adenomas per Colonoscopy:}

ADR can overlook differences in colonoscopy quality, as endoscopists with the same ADR could be detecting highly variable numbers of adenomas per colonoscopy ${ }^{51,52}$. Denis et al analyzed over 42000 colonoscopies performed by 316 endoscopists in France ${ }^{51}$. They evaluated the mean number of adenomas per procedure (MAP, total number of adenomas detected divided by the number of colonoscopies); for colonoscopists with ADR around 35\%, the MAP varied markedly between 0.36 and 0.98. Wang et al compared 2 groups of endoscopists, serving the same patient pool in Los Angeles, California, at a tertiary care teaching hospital and at 3 non-teaching facilities ${ }^{52}$. Both groups had fairly similar ADRs (28.8\% and 25.7\%; $p=0.052$ ). The authors assessed the MAP, as well as another suggested metric, the ADR-Plus (mean number of adenomas detected after the first adenoma, in procedures in which at least one adenoma was found). They found that the teaching group had $23.5 \%$ higher MAP and 29.5\% higher ADR-Plus.

Coupling ADR with another total adenoma metric has therefore been suggested by both previous groups to better assess colonoscopists' performance ${ }^{51,52}$. Similarly, Lee et al proposed two measures of total adenoma detection to complement the ADR: MAP and MAP+ (mean adenoma per positive procedure, calculated as total number of adenomas detected divided by the number of colonoscopies in which at least one adenoma was detected $)^{53}$.

Adding a total adenoma detection metric provides a more comprehensive assessment of the thoroughness of the colonoscopic exam, provides better discrimination between endoscopists and limits potential inclination to "gaming", i.e. a less thorough examination once a first adenoma is detected and resected. However, this makes the assessment much more labor-intensive. Further, this could be an incentive to separate polyps from the same colon segment into different specimen bottles, leading to increased colonoscopy costs. In the absence of formally established benchmarks, and while adherence 
to measuring ADR remains far from optimal in routine practice, total adenoma detection metrics will primarily be applied in research settings in the short term.

\section{ADR Benchmarks:}

The ADR targets originally defined in 2002 ( $\geq 25 \%$ for men and $\geq 15 \%$ for women ${ }^{24}$ ) may be outdated. Several recent studies revealed ADRs reaching the $40 \%-50 \%$ range or higher in average-risk individuals ${ }^{40}$, $44,48,53$. Demographic features, other than gender, also affect the prevalence of adenomas ${ }^{54}$; this includes increasing prevalence with age, and more proximal adenomas in blacks compared to whites ${ }^{55}$. As ADR use becomes more prevalent in clinical practice and in different populations, benchmark adjustments will be necessary based on the specific characteristics of the screened demographic group and the most recent ADRs reported in the literature that have been proven to provide cancer prevention.

\section{Advanced Adenomas:}

Measuring the advanced ADR might be more clinically relevant, as advanced adenomas are more prone to progress to $C R C^{56}$. Similar to $A D R$, the is significant variability in advanced $A D R$ between colonoscopists $^{17,57}$. Among 9 colonoscopists in Indianapolis, detection of adenomas $\geq 1 \mathrm{~cm}$ in size varied from $1.7 \%$ to $6.2 \%{ }^{17}$. Among 14 colonoscopists in Chicago, advanced ADR varied from $2 \%$ to $18.18 \%{ }^{57}$.

This study ${ }^{57}$ generated concerns, because it showed that colonoscopists' advanced ADR were independent of their non-advanced ADR (correlation $-0.42 ; 95 \% \mathrm{Cl}-0.77-0.14, \mathrm{p}=0.13$ ). In addition, the study by Wang et $\mathrm{al}^{52}$ showed that the teaching group had a $28.7 \%$ higher advanced ADR, compared to 
the non-teaching group, whereas ADRs were similar for both groups. These results suggest that some colonoscopists might have adequate ADRs, while missing a significant number of advanced adenomas. These findings warrant future investigation, as they could carry important implications in assessing colonoscopy quality. However, using advanced ADR as a quality metric will likely prove to be very challenging, because of variable polyp size measurement by endoscopists, and large inter-observer variability for villous elements among pathologists.

\section{Serrated Polyps:}

An inherent limitation of the ADR is that it does not account for the detection of serrated polyps. This might be problematic as recent evidence suggests that the serrated pathway likely accounts for up to one third of all $\mathrm{CRCs}^{58,59}$. Endoscopic detection of serrated polyps is more challenging than detection of adenomatous lesions, as they are have a subtle, pale appearance and indistinct margins ${ }^{60}$. The prevalence of serrated polyps in the right colon in average-risk patients is higher than previously reported, with a mean of $13 \%$ in a recent study by our group ${ }^{61}$.

The variability in detecting proximal colon serrated lesions is more striking compared to ADR, ranging

from 5 to 18 fold among endoscopists, whereas ADR variation is typically around 3 to 4 fold ${ }^{38,62,63}$. In two recent studies, detection rates varied from $1 \%$ to $18 \%$ among 15 academic gastroenterologists who performed a total of 6681 screening colonoscopies ${ }^{62}$, and from $6 \%$ to $22 \%$ among 5 colonoscopists who completed 1354 screening exams ${ }^{38}$.

Interestingly, and despite the variation in detection of proximal serrated lesions, there appears to be a strong correlation between it and $\mathrm{ADR}^{61}$. This was the case in both men (correlation $0.71, \mathrm{p}=0.003$ ) and women (correlation $0.73, \mathrm{p}=0.002)^{61}$. Therefore, while not directly capturing serrated polyps, ADR might 
still be valid by itself to assess both adenomatous and serrated lesions. This has important practical implications because of several problems impacting the use of serrated polyp detection rate as a quality metric: there are currently no endorsed benchmarks for sessile lesions detection rates; the measurement should only include lesions proximal to the sigmoid colon to avoid the confounding effect of hyperplastic polyps from the rectosigmoid (whereas it is difficult to reliably identify the junction between the sigmoid and the descending colon); and the histological classification of serrated lesions remains challenging and variable in practice ${ }^{63}$.

\section{Incomplete Adenoma Resection:}

Several studies evaluating interval CRCs found that these cancers can be attributed to incomplete polypectomy in about $10 \%$ to $30 \%$ of cases $^{13,20,22,64,65}$. Since ADR is essentially geared at assessing detection and not resection, the inadequate quality in these cases would not be reflected by measuring the ADR. Competent colonoscopists should be able to fully resect most sessile polyps up to $2 \mathrm{~cm}$ in size and all mucosally based pedunculated polyps ${ }^{24}$.

In the CARE study, Pohl et al assessed the completeness of resection based on 346 polypectomies performed in 269 patients by 11 colonoscopists ${ }^{66}$. Polyps assessed were sessile or flat, ranged from 5 to $20 \mathrm{~mm}$ in size, and $59 \%$ were in the right colon. The evaluation was based on a biopsy protocol of the margins of the polypectomy site, and revealed an incomplete resection in $10.1 \%$ of cases. In addition, there was a wide variability in incomplete resection rate, ranging from $6.5 \%$ to $22.7 \%$ between endoscopists. Of note, serrated lesions were more likely to be incompletely resected compared to adenomatous polyps ( $31 \%$ vs $7.2 \%, \mathrm{p}<0.001)$. 
Polypectomy technique and effectiveness is a key component of colonoscopy quality. While awareness is increasing about its variability between colonoscopists, assessing its quality is challenging because it is more difficult than assessing detection quality. However this should not be an absolute deterrent. A group from the UK recently published work to develop and validate a tool to assess polypectomy skills using video reviews ${ }^{67}$, but further research is needed..

\section{Implementation of Quality Measurement:}

Assessing colonoscopy quality in day-to-day practice should no longer be optional for endoscopists. It is our duty to patients to provide them the best possible prevention against CRC. Measuring competency, and when necessary improving it, can ensure that colonoscopists are held accountable to quality standards.

\section{Process Planning:}

The initial step in establishing a colonoscopy quality program is to select the metric that will be assessed $^{26}$. This metric should be measured according to clearly defined parameters, and the measurement method should be precise and consistent. Metrics with well-established benchmarks are likely more useful to gauge performance related to standards. Once the metric and the measurement method are determined, a baseline data collection can be carried out. According to the measurement 
results, it can be decided if improvement is required to achieve high value colonoscopy. Repeat data collection will allow to assess the progress.

For endoscopists, the first step in this process is to regularly measure ADR, and if warranted, take action to improve it ${ }^{68}$. Similar considerations apply at the level of an endoscopy center. Hilsden et al shared their process and experience in implementing a colonoscopy quality assurance program at their endoscopy facility in Calgary, Canada ${ }^{69}$. Participation in the quality monitoring program was a requirement to be granted endoscopy privileges at the center. Their program included several aspects, one of which was distribution of report cards to endoscopists, reflecting measurements of their collected indicators, with comparison to the entire group of endoscopists at the center. Metrics reported in the early phase of the program were cecal intubation rate, average withdrawal time and polyp detection rate. Subsequently, the reports included various measures of adenoma detection rate.

On a larger scale, audits can be conducted to assess the quality colonoscopy. In the UK, the results of a 2011 nationwide audit were recently published $^{70}$, and included two main quality metrics: cecal intubation rate and polyp detection rate. Compared to the previous audit results from 1999, the cecal intubation rate improved from $76.9 \%$ to $92.3 \%$, and the polyp detection rate increased from $22.5 \%$ to 32.1\%. These examples reflect the feasibility and benefit of implementing colonoscopy quality assessment initiatives.

\section{Resources to Facilitate Implementation:}

Quality measurement for colonoscopy cannot be achieved without adequate procedure documentation

. It is fundamental to have complete data to accurately measure quality metrics, and standardized electronic reports can facilitate this process. . In 2007, the Quality Assurance Task Force of the National 
Colorectal Cancer Roundtable developed a reporting and data system for colonoscopy (CO-RADS) to facilitate quality monitoring within and across practices ${ }^{71}$. Several commercially available endoscopy software programs generate electronic reports that include the elements suggested in CO-RADS.

A group from the Netherlands created a structured colonoscopy reporting system (EndoALPHA) that mandates endoscopists to document various quality indicators, and that automatically generates quality measurement reports ${ }^{72}$. The Clinical Outcomes Research Initiative (CORI) developed a software that captures most of the indicators proposed in CO-RADS ${ }^{73}$. The CORI consortium included 73 practices from 24 states in the United States; they electronically submitted their colonoscopy reports to the database for analysis to measure and improve quality.

The Gastroenterology societies have established two registries to assist individual endoscopists and practice groups in monitoring colonoscopy quality: GIQuIC (GI Quality Improvement Consortium; developed by the American College of Gastroenterology and the American Society of Gastrointestinal Endoscopy) and DHOR (Digestive Health Outcome Registry; developed by the American Gastroenterology Association). Submitting colonoscopy reports to these registries will generate performance reports for gastroenterologists, assessing various metrics, with ADR being the most important.

Natural language processing (NLP) is a medical informatics tool that identifies and extracts information from free-text reports, using artificial intelligence. NLP can retrieve data necessary for colonoscopy quality measurement with high accuracy, specifically adenoma detection metrics ${ }^{74}$. NLP can be helpful in easily quantifying quality metrics for endoscopists, and awaits further study for validation and standardization. . 


\section{Interventions to Improve Quality:}

Ideally, a colonoscopy quality improvement program should allow identifying underperformers in order to pursue interventions that will improve their performance. The benefit of various interventions is quite variable, and the optimal approach to ameliorate substandard effectiveness is yet to be identified $^{75}$.

\section{Withdrawal Time Interventions:}

Targeting a longer withdrawal time in colonoscopists with low ADR has been evaluated by several studies. Simply recording withdrawal time did not have a significant effect on increasing overall polyp detection rate $^{76}$. Longer withdrawal time might improve serrated polyps detection rate in the proximal $\operatorname{colon}^{38}$. Forcing endoscopists to spend at least 7 minutes on withdrawal did not affect polyp detection rate $^{77}$; this reflects that a forced increase in WT is not spent in effective inspection, when it is not paired with education about withdrawal and inspection techniques.

The most beneficial intervention involving withdrawal time was undertaken by Barclay et al ${ }^{78}$. It started with a group review of optimal inspection techniques, followed by implementation of a segmental withdrawal protocol: at least 2 minutes per colonic segment, indicated by a digital stopwatch beeps; with a total withdrawal duration of 8 minutes minimum. This resulted in a significant increase of the ADR from $23.5 \%$ to $34.7 \%(p<0.0001)$.

\section{Educational Interventions:}

In Barclay's et al intervention ${ }^{78}$, the education component, that preceded the withdrawal protocol implementation, likely played an important role. The Endoscopic Quality Improvement Program (EQUIP) is a recently described educational process ${ }^{79}$. Endoscopists who were assigned to the training (2 sessions: techniques of high quality colonoscopy; and polyps overview and classification) increased their 
ADR from $36 \%$ at baseline to $47 \%$ after training $(p=0.0013)$ - whereas the untrained group ADR remained unchanged at $35 \%$.

Adler et al found that the number of Continuing Medical Education (CME) meetings attended by colonoscopists correlated with their ADR $(p=0.012)^{19}$. The authors suggested that a better understanding of polyp morphology and examination techniques, taught at the meetings, resulted in better colonoscopy performance. Educational programs, whether at local or larger scales, have an important role in improving adenoma detection and resection, as well as recognition and removal of serrated lesions.

Feedback Methods:

In the EQUIP study ${ }^{79}$, it should be noted that the training group also received monthly ADR feedback. This might have contributed to the observed benefit. Harewood et al provided quarterly feedback to a group of 58 endoscopists, and noted a $19 \%$ decline in incomplete colonoscopies ${ }^{80}$. Lin et al also reported that monitoring and feedback aided quality improvement, with increases in mean withdrawal time and polyp (but not adenoma) detection rate $(33.1 \% \text { to } 38.1 \%, p=0.04)^{81}$. Implementation of a quarterly report card resulted in a significant increase in cecal intubation rate $(98.1 \%$ vs $95.6 \%, p=0.027)$ and in $\operatorname{ADR}(53.9 \% \text { vs } 44.7 \%, p=0.013)^{48}$; the increment in adenoma detection was mostly due to increased detection of proximal adenomas.

The impact of feedback has not been consistently significant, and several other groups that used feedback interventions reported negative results ${ }^{75}$. Shaukat et al applied a series of systematic interventions over a 3-year period, including feedback and educational programs, but were not successful at improving endoscopists' $A D R^{82}$.

Video-monitoring: 
Rex et al assessed the impact of video recording on the quality of colonoscopy performance ${ }^{83}$. Endoscopists' awareness of the recording resulted in 49\% increase of mean inspection time, and $31 \%$ improvement in mucosal inspection technique. Whether this improves ADR remains to be seen, but Madhoun et al recently reported that video recording was associated with a non-significant increase in ADR (while hyperplastic detection increased significantly) ${ }^{84}$.

Researchers at the Mayo Clinic created an Endoscopic Multimedia Information System (EMIS) which involves recording, monitoring and assessing colonoscopies ${ }^{85}$. The system is being developed to allow real-time analysis and as needed feedback related to routine colonoscopy maneuvers, in order to achieve high quality with each colonoscopy.

Video-monitoring or advanced automated assessment systems could prove valuable to complement the current interventions used to enhance colonoscopy quality, especially that many of these interventions have limited effectiveness.

\section{References:}


1. Lieberman DA, Rex DK, Winawer SJ, et al. Guidelines for colonoscopy surveillance after screening and polypectomy: a consensus update by the US Multi-Society Task Force on Colorectal Cancer. Gastroenterology 2012;143:844-57.

2. Winawer SJ, Zauber $\mathrm{AG}, \mathrm{Ho} \mathrm{MN}$, et al. Prevention of colorectal cancer by colonoscopic polypectomy. The National Polyp Study Workgroup. N Engl J Med 1993;329:1977-81.

3. Thiis-Evensen E, Hoff GS, Sauar J, et al. Population-based surveillance by colonoscopy: effect on the incidence of colorectal cancer. Telemark Polyp Study I. Scand J Gastroenterol 1999;34:41420.

4. Citarda F, Tomaselli G, Capocaccia R, et al. Efficacy in standard clinical practice of colonoscopic polypectomy in reducing colorectal cancer incidence. Gut 2001;48:812-5.

5. Robertson DJ, Greenberg ER, Beach $M$, et al. Colorectal cancer in patients under close colonoscopic surveillance. Gastroenterology 2005;129:34-41.

6. Kahi CJ, Imperiale TF, Juliar BE, et al. Effect of screening colonoscopy on colorectal cancer incidence and mortality. Clin Gastroenterol Hepatol 2009;7:770-5; quiz 711.

7. Singh $\mathrm{H}$, Nugent $\mathrm{Z}$, Mahmud SM, et al. Predictors of colorectal cancer after negative colonoscopy: a population-based study. Am J Gastroenterol 2010;105:663-73; quiz 674.

8. Brenner $\mathrm{H}$, Chang-Claude J, Seiler CM, et al. Protection from colorectal cancer after colonoscopy: a population-based, case-control study. Ann Intern Med 2011;154:22-30.

9. Mulder SA, van Soest EM, Dieleman JP, et al. Exposure to colorectal examinations before a colorectal cancer diagnosis: a case-control study. Eur J Gastroenterol Hepatol 2010;22:437-43.

10. Bressler B, Paszat LF, Chen Z, et al. Rates of new or missed colorectal cancers after colonoscopy and their risk factors: a population-based analysis. Gastroenterology 2007;132:96-102.

11. Singh $\mathrm{H}$, Nugent Z, Demers AA, et al. Rate and predictors of early/missed colorectal cancers after colonoscopy in Manitoba: a population-based study. Am J Gastroenterol 2010;105:2588-96. 
12. Baxter NN, Sutradhar R, Forbes SS, et al. Analysis of administrative data finds endoscopist quality measures associated with postcolonoscopy colorectal cancer. Gastroenterology 2011;140:65-72.

13. Farrar WD, Sawhney MS, Nelson DB, et al. Colorectal cancers found after a complete colonoscopy. Clin Gastroenterol Hepatol 2006;4:1259-64.

14. Cooper GS, Xu F, Barnholtz Sloan JS, et al. Prevalence and predictors of interval colorectal cancers in medicare beneficiaries. Cancer 2012;118:3044-52.

15. Brenner $\mathrm{H}$, Chang-Claude J, Seiler $\mathrm{CM}$, et al. Interval cancers after negative colonoscopy: population-based case-control study. Gut 2012;61:1576-82.

16. Hewett DG, Kahi CJ, Rex DK. Does colonoscopy work? J Natl Compr Canc Netw 2010;8:67-76; quiz 77.

17. Chen SC, Rex DK. Endoscopist can be more powerful than age and male gender in predicting adenoma detection at colonoscopy. Am J Gastroenterol 2007;102:856-61.

18. Ko CW, Dominitz JA, Green P, et al. Specialty differences in polyp detection, removal, and biopsy during colonoscopy. Am J Med 2010;123:528-35.

19. Adler A, Wegscheider K, Lieberman D, et al. Factors determining the quality of screening colonoscopy: a prospective study on adenoma detection rates, from 12,134 examinations (Berlin colonoscopy project 3, BECOP-3). Gut 2013;62:236-41.

20. Robertson DJ, Lieberman DA, Winawer SJ, et al. Colorectal cancers soon after colonoscopy: a pooled multicohort analysis. Gut 2014;63:949-56.

21. Pohl H, Robertson DJ. Colorectal cancers detected after colonoscopy frequently result from missed lesions. Clin Gastroenterol Hepatol 2010;8:858-64.

22. le Clercq CM, Bouwens MW, Rondagh EJ, et al. Postcolonoscopy colorectal cancers are preventable: a population-based study. Gut 2014;63:957-63. 
23. Huang Y, Gong W, Su B, et al. Risk and cause of interval colorectal cancer after colonoscopic polypectomy. Digestion 2012;86:148-54.

24. Rex DK, Petrini JL, Baron TH, et al. Quality indicators for colonoscopy. Am J Gastroenterol 2006;101:873-85.

25. Fayad NF, Kahi CJ. Quality Measures for Colonoscopy: A Critical Evaluation. Clin Gastroenterol Hepatol 2013.

26. Calderwood AH, Jacobson BC. Colonoscopy quality: metrics and implementation. Gastroenterol Clin North Am 2013;42:599-618.

27. Rex DK. Can we fix colonoscopy?...Yes! Gastroenterology 2011;140:19-21.

28. Weinberg DS. Colonoscopy: what does it take to get it "right"? Ann Intern Med 2011;154:68-9.

29. Kahi CJ, Anderson JC, Rex DK. Screening and surveillance for colorectal cancer: state of the art. Gastrointest Endosc 2013;77:335-50.

30. Rex DK. Quality in colonoscopy: cecal intubation first, then what? Am J Gastroenterol 2006;101:732-4.

31. Cotton PB, Connor P, McGee D, et al. Colonoscopy: practice variation among 69 hospital-based endoscopists. Gastrointest Endosc 2003;57:352-7.

32. Aslinia F, Uradomo L, Steele A, et al. Quality assessment of colonoscopic cecal intubation: an analysis of 6 years of continuous practice at a university hospital. Am J Gastroenterol 2006;101:721-31.

33. Hosokawa O, Shirasaki S, Kaizaki Y, et al. Invasive colorectal cancer detected up to 3 years after a colonoscopy negative for cancer. Endoscopy 2003;35:506-10.

34. Leaper M, Johnston MJ, Barclay M, et al. Reasons for failure to diagnose colorectal carcinoma at colonoscopy. Endoscopy 2004;36:499-503. 
35. Rex DK. Colonoscopic withdrawal technique is associated with adenoma miss rates. Gastrointest Endosc 2000;51:33-6.

36. Barclay RL, Vicari JJ, Doughty AS, et al. Colonoscopic withdrawal times and adenoma detection during screening colonoscopy. N Engl J Med 2006;355:2533-41.

37. Imperiale TF, Glowinski EA, Juliar BE, et al. Variation in polyp detection rates at screening colonoscopy. Gastrointest Endosc 2009;69:1288-95.

38. de Wijkerslooth TR, Stoop EM, Bossuyt PM, et al. Differences in proximal serrated polyp detection among endoscopists are associated with variability in withdrawal time. Gastrointest Endosc 2013;77:617-23.

39. Moritz V, Bretthauer M, Ruud HK, et al. Withdrawal time as a quality indicator for colonoscopy a nationwide analysis. Endoscopy 2012;44:476-81.

40. Lee TJ, Blanks RG, Rees CJ, et al. Longer mean colonoscopy withdrawal time is associated with increased adenoma detection: evidence from the Bowel Cancer Screening Programme in England. Endoscopy 2013;45:20-6.

41. Shaukat $\mathrm{A}$, Rector $\mathrm{T}$, Church $\mathrm{T}$, et al. Withdrawal times, adenoma detection rates, and risk of interval cancer. Am J Gastroenterol 2014;109:S613.

42. Rex DK. Optimal withdrawal and examination in colonoscopy. Gastroenterol Clin North Am 2013;42:429-42.

43. Kaminski MF, Regula J, Kraszewska E, et al. Quality indicators for colonoscopy and the risk of interval cancer. N Engl J Med 2010;362:1795-803.

44. Corley DA, Jensen CD, Marks AR, et al. Adenoma detection rate and risk of colorectal cancer and death. N Engl J Med 2014;370:1298-306.

45. Do A, Weinberg J, Kakkar A, et al. Reliability of adenoma detection rate is based on procedural volume. Gastrointest Endosc 2013;77:376-80. 
46. Rex DK, Eid E. Considerations regarding the present and future roles of colonoscopy in colorectal cancer prevention. Clin Gastroenterol Hepatol 2008;6:506-14.

47. Bretagne JF, Ponchon T. Do we need to embrace adenoma detection rate as the main quality control parameter during colonoscopy? Endoscopy 2008;40:523-8.

48. Kahi CJ, Ballard D, Shah AS, et al. Impact of a quarterly report card on colonoscopy quality measures. Gastrointest Endosc 2013;77:925-31.

49. Williams JE, Le TD, Faigel DO. Polypectomy rate as a quality measure for colonoscopy. Gastrointest Endosc 2011;73:498-506.

50. Williams JE, Holub JL, Faigel DO. Polypectomy rate is a valid quality measure for colonoscopy: results from a national endoscopy database. Gastrointest Endosc 2012;75:576-82.

51. Denis B, Sauleau EA, Gendre I, et al. The mean number of adenomas per procedure should become the gold standard to measure the neoplasia yield of colonoscopy: a population-based cohort study. Dig Liver Dis 2014;46:176-81.

52. Wang HS, Pisegna J, Modi R, et al. Adenoma detection rate is necessary but insufficient for distinguishing high versus low endoscopist performance. Gastrointest Endosc 2013;77:71-8.

53. Lee TJ, Rutter MD, Blanks RG, et al. Colonoscopy quality measures: experience from the NHS Bowel Cancer Screening Programme. Gut 2012;61:1050-7.

54. Lieberman DA, Holub J, Eisen $\mathrm{G}$, et al. Prevalence of polyps greater than $9 \mathrm{~mm}$ in a consortium of diverse clinical practice settings in the United States. Clin Gastroenterol Hepatol 2005;3:798805.

55. Corley DA, Jensen CD, Marks AR, et al. Variation of adenoma prevalence by age, sex, race, and colon location in a large population: implications for screening and quality programs. Clin Gastroenterol Hepatol 2013;11:172-80. 
56. Brenner $\mathrm{H}$, Hoffmeister $\mathrm{M}$, Stegmaier $\mathrm{C}$, et al. Risk of progression of advanced adenomas to colorectal cancer by age and sex: estimates based on 840,149 screening colonoscopies. Gut 2007;56:1585-9.

57. Greenspan M, Rajan KB, Baig A, et al. Advanced adenoma detection rate is independent of nonadvanced adenoma detection rate. Am J Gastroenterol 2013;108:1286-92.

58. Snover DC. Update on the serrated pathway to colorectal carcinoma. Hum Pathol 2011;42:1-10.

59. Rex DK, Ahnen DJ, Baron JA, et al. Serrated lesions of the colorectum: review and recommendations from an expert panel. Am J Gastroenterol 2012;107:1315-29; quiz 1314, 1330.

60. Sweetser S, Smyrk TC, Sinicrope FA. Serrated colon polyps as precursors to colorectal cancer. Clin Gastroenterol Hepatol 2013;11:760-7; quiz e54-5.

61. Kahi CJ, Li X, Eckert GJ, et al. High colonoscopic prevalence of proximal colon serrated polyps in average-risk men and women. Gastrointest Endosc 2012;75:515-20.

62. Kahi CJ, Hewett DG, Norton DL, et al. Prevalence and variable detection of proximal colon serrated polyps during screening colonoscopy. Clin Gastroenterol Hepatol 2011;9:42-6.

63. Hetzel JT, Huang CS, Coukos JA, et al. Variation in the detection of serrated polyps in an average risk colorectal cancer screening cohort. Am J Gastroenterol 2010;105:2656-64.

64. Leung K, Pinsky $\mathrm{P}$, Laiyemo AO, et al. Ongoing colorectal cancer risk despite surveillance colonoscopy: the Polyp Prevention Trial Continued Follow-up Study. Gastrointest Endosc 2010;71:111-7.

65. Pabby A, Schoen RE, Weissfeld JL, et al. Analysis of colorectal cancer occurrence during surveillance colonoscopy in the dietary Polyp Prevention Trial. Gastrointest Endosc 2005;61:38591. 
66. Pohl H, Srivastava A, Bensen SP, et al. Incomplete polyp resection during colonoscopy-results of the complete adenoma resection (CARE) study. Gastroenterology 2013;144:74-80 e1.

67. Gupta S, Anderson J, Bhandari P, et al. Development and validation of a novel method for assessing competency in polypectomy: direct observation of polypectomy skills. Gastrointest Endosc 2011;73:1232-9 e2.

68. Hewett DG, Kahi CJ, Rex DK. Efficacy and effectiveness of colonoscopy: how do we bridge the gap? Gastrointest Endosc Clin N Am 2010;20:673-84.

69. Hilsden RJ, Rostom A, Dube C, et al. Development and implementation of a comprehensive quality assurance program at a community endoscopy facility. Can J Gastroenterol 2011;25:54754.

70. Gavin DR, Valori RM, Anderson JT, et al. The national colonoscopy audit: a nationwide assessment of the quality and safety of colonoscopy in the UK. Gut 2013;62:242-9.

71. Lieberman D, Nadel M, Smith RA, et al. Standardized colonoscopy reporting and data system: report of the Quality Assurance Task Group of the National Colorectal Cancer Roundtable. Gastrointest Endosc 2007;65:757-66.

72. van Doorn SC, van Vliet J, Fockens $\mathrm{P}$, et al. A novel colonoscopy reporting system enabling quality assurance. Endoscopy 2014;46:181-7.

73. Lieberman DA, Faigel DO, Logan JR, et al. Assessment of the quality of colonoscopy reports: results from a multicenter consortium. Gastrointest Endosc 2009;69:645-53.

74. Imler TD, Morea J, Kahi C, et al. Natural language processing accurately categorizes findings from colonoscopy and pathology reports. Clin Gastroenterol Hepatol 2013;11:689-94.

75. Corley DA, Jensen CD, Marks AR. Can we improve adenoma detection rates? A systematic review of intervention studies. Gastrointest Endosc 2011;74:656-65. 
76. Taber A, Romagnuolo J. Effect of simply recording colonoscopy withdrawal time on polyp and adenoma detection rates. Gastrointest Endosc 2010;71:782-6.

77. Sawhney MS, Cury MS, Neeman N, et al. Effect of institution-wide policy of colonoscopy withdrawal time $>$ or $=7$ minutes on polyp detection. Gastroenterology 2008;135:1892-8.

78. Barclay RL, Vicari JJ, Greenlaw RL. Effect of a time-dependent colonoscopic withdrawal protocol on adenoma detection during screening colonoscopy. Clin Gastroenterol Hepatol 2008;6:1091-8.

79. Coe SG, Crook JE, Diehl NN, et al. An endoscopic quality improvement program improves detection of colorectal adenomas. Am J Gastroenterol 2013;108:219-26; quiz 227.

80. Harewood GC, Petersen BT, Ott BJ. Prospective assessment of the impact of feedback on colonoscopy performance. Aliment Pharmacol Ther 2006;24:313-8.

81. Lin OS, Kozarek RA, Arai A, et al. The effect of periodic monitoring and feedback on screening colonoscopy withdrawal times, polyp detection rates, and patient satisfaction scores. Gastrointest Endosc 2010;71:1253-9.

82. Shaukat $\mathrm{A}$, Oancea $\mathrm{C}$, Bond $\mathrm{JH}$, et al. Variation in detection of adenomas and polyps by colonoscopy and change over time with a performance improvement program. Clin Gastroenterol Hepatol 2009;7:1335-40.

83. Rex DK, Hewett DG, Raghavendra $M$, et al. The impact of videorecording on the quality of colonoscopy performance: a pilot study. Am J Gastroenterol 2010;105:2312-7.

84. Madhoun MF, Tierney WM. The impact of video recording colonoscopy on adenoma detection rates. Gastrointest Endosc 2012;75:127-33.

85. de Groen PC. Advanced systems to assess colonoscopy. Gastrointest Endosc Clin N Am 2010;20:699-716. 